\title{
Diversity Analysis of Sesame Lignans in 40 Sesame Collections in Tamil Nadu, India
}

\author{
Ghane Ajit ${ }^{*}$, D. Uma ${ }^{2}$, S. Manonmani ${ }^{3}$, B. Vinothkumar ${ }^{4}$ and S. Rajesh $^{1}$ \\ ${ }^{1}$ Department of Plant Biotechnology, ${ }^{2}$ Department of Biochemistry, \\ ${ }^{3}$ Department of Oilseeds, ${ }^{4}$ Department of Entomology, Tamil Nadu Agricultural University, \\ Coimbatore 641 003, Tamilnadu, India \\ *Corresponding author
}

Keywords

Sesame, Lignan,

Sesamin,

Sesamolin, HPLC

Article Info

Accepted:

17 May 2019

Available Online:

10 June 2019

\section{A B S T R A C T}

Sesame (Sesamum indicum L.) is an important oilseed crop possessing medicinal values and commonly cultivated in tropical and sub-tropical areas around the world. The therapeutic value of sesamum is attributed to lignans, a prime secondary metabolite. We used High Performance Liquid Chromatography to analyse the variation of sesame lignans especially sesamin and sesamolin, the major lignans from lignan family, in 40 sesame lines maintained in Tamil Nadu Agricultural University, Tamil Nadu. HPLC results showed that sesamin, sesamolin and total lignan contents in sesame lines ranged from 0.08 to 2.58 $\mathrm{mg} / \mathrm{g}, 0.28$ to 2.52 and 0.49 to $4.55 \mathrm{mg} / \mathrm{g}$, respectively. Among the 40 sesame lines $50 \%$ lines stayed in range 3 to $5 \mathrm{mg} / \mathrm{g}$ in total lignin content. On an average, sesame lines with brown and black seed coat colours had highest total lignan contents than yellow or white seed coat colour sesame lines. The correlation of variation between sesame lines with different seed coat colours ranked as yellow $(69 \%)>$ black $(35 \%)>$ brown $(30 \%)>$ white (29\%). This study emphasises the need to investigate variation in lignan contents in sesame seed lines to develop superior sesame genotypes.

\section{Introduction}

Sesame belongs to the genus Sesamum, one of 16 genera in the family Pedaliaceae. The genus Sesamum comprises of about 35 wild species besides the only cultivated species, Sesamum indicum. Sesamum indicumis the major commercial source of sesame seeds and is primarily grown in Burma, India, China, Ethiopia and Sudan with 9,398,770 ha under sesame cultivation worldwide, producing 4.76 million tons (FAO, 2013).
Sesame seeds contain high oil and protein accounting to about 50\% and 25\% respectively. Sesame protein is rich in arginine, leucine and the sulphur containing amino acids cysteine and methionine but slightly low in the essential amino acid lysine. The fatty acid profile of sesame oil reflects linoleic acid (37-47\%), oleic acid (35-43\%), palmitic (9-11\%) and stearic acid (5-10\%) with trace amount of linolenic acid (Latif and Anwar, 2011). Sesame oil isa valuable edible oil with a composition that provides good health benefits including high level of 
unsaturated fatty acids and antioxidants (Bisht et al., 1998). Sesame seed oil has significant antimicrobial activity against many bacteria and fungi (Hussein et al., 2016). Sesame seed is highly valued for its oil which is exceptionally resistant to oxidative rancidity as compared to other vegetable oils (Hemalatha, 2004). Sesame seed contains a group of compounds collectively known as lignans, to which many health promoting effects are attributed.

Lignans, a group of secondary metabolites are responsible for the therapeutic value of sesame oil. Sesame lignans, especially sesamin and sesamolin possesses various biological activities attributing to its health promoting effects. These two compounds have been reported to have multiple pharmacological properties, such as antioxidant activity (Shahidi et al., 2006), antiproliferative activity (Yokota et al., 2007) and anti-inflammatory function (Hsu et al., 2005). In addition, anti-cholesterolemic and antihypertensive properties of sesamin have beenreported (Penalvo et al., 2006). Lignans, the natural anti-oxidants in sesame oil prevent oxidative rancidity and provide high stability and improved the shelf life of the oil (Suja et al., 2005). The benefits of lignans on human health being well established, it is important to select a high lignan especially sesamin and sesamolin germplasm that are ideal for edible, therapeutic and industrial purposes. The objective of present study is to investigate the content of lignans especially sesamin and sesamolin, in sesame lines maintained at Tamil Nadu Agricultural University, Tamil Nadu.

\section{Materials and Methods}

\section{Materials and Chemicals}

40 sesame lines maintained in the Department of Oilseeds, Tamil Nadu Agricultural
University, Tamil Nadu were used in present study [coat colour: brown $(\mathrm{n}=23)$, black $(n=6)$, yellow $(n=8)$, white $(n=3)]$. Lignan stand ards and methanol (HPLC grade) were purchased from Sigma-Aldrich. Calibration curves were prepared by injecting varying concentration of working stand ard in HPLC system.

\section{Sample Preparation}

Samples were prepared according to the method of Shi et al., (2017) with some modifications. Briefly, $0.2 \mathrm{mg}$ of seed sample was crushed in mortar and pestle with $5 \mathrm{ml}$ of methanol. The extract was shaken vigorously for 2 minutes using a vortex mixer and sonicated for 2 minutes. Samples were then centrifuged at 10,000 rpm for $5 \mathrm{~min}$. and the supernatant was collected. The residue was re-extracted with another $2 \mathrm{~mL}$ of methanol. The supernatants were pooled and the final volume of each extract was made up to $5 \mathrm{~mL}$. Prior to HPLC analysis it was filtered through a $0.45-\mu \mathrm{m}$ nylon membrane.

\section{HPLC Analysis}

The quantitation of sesamin and sesamolin in the sesame seed was achieved by HPLC-DAD system (Agilent 1220 Infinity II LC of Agilent Technologies Co., USA) including a binary pump, an auto-sampler, temperaturecontrolled column oven and a diode array detector (DAD). The separation was carried out on a reversed-phase C18 column $(150 \mathrm{~mm}$ $\times 4.6 \mathrm{~mm}$ i.d., $5 \mu \mathrm{m}$ ) under the following chromatographic conditions: the injection volume was $10 \mu \mathrm{L}$, column temperature was maintained at $30^{\circ} \mathrm{C}$, wavelength of $\mathrm{UV}$ detection was set at $290 \mathrm{~nm}$ and mobile phase consisted of methanol and Milli-Q water $(70 / 30, \mathrm{v} / \mathrm{v})$ with a flow rate of $1.0 \mathrm{~mL} / \mathrm{min}$. Data analysis was performed in Excel and Statistical Package for the Social Sciences (SPSS) 16. 


\section{Results and Discussion}

Forty sesame lines collections maintained in Tamil Nadu Agricultural University, Tamil Nadu were analysed by HPLC for separation of isolated lignans especially sesamin and sesamolin, the major lignans from lignan family. The HPLC system yielded two fractions at $9.5 \mathrm{~min}$. and $12.5 \mathrm{~min}$. corresponding to sesamin and sesamolin respectively (Fig. 1). The sesamin and sesamolin content in 40 sesame lines are listed in Table 1 . The present study reveals that the total lignan (sesamin and sesamolin) contents of these lines ranged from $0.49 \mathrm{mg} / \mathrm{g}$ to $4.55 \mathrm{mg} / \mathrm{g}$ with an average of $2.69 \mathrm{mg} / \mathrm{g}$. The sesamin content of these sesame lines ranged from $0.08 \mathrm{mg} / \mathrm{g}$ to $2.58 \mathrm{mg} / \mathrm{g}$ with an average of $1.28 \mathrm{mg} / \mathrm{g}$. The sesamolin content of these lines ranged from $0.28 \mathrm{mg} / \mathrm{g}$ to 2.52 $\mathrm{mg} / \mathrm{g}$ with an average $1.41 \mathrm{mg} / \mathrm{g}$. The total lignancontent reported in the present study is higher than the values reported earlier in sesame lines of Tamil Nadu (Pathak et al., 2015). The highest total lignan content was recorded in sesame line KMR-108 (4.55 $\mathrm{mg} / \mathrm{g}$ ), a brown seed coat line followed by SI$3106(4.48 \mathrm{mg} / \mathrm{g})$, SI-1236 (4.17 mg/g). Distribution of 40 sesame lines according to their lignin contents are shown in Figure 2. The distribution result showed about $50 \%$ of sesame lines stayed in the range of 3 to 5 $\mathrm{mg} / \mathrm{g}$. Among these only four sesame seed lines stayed in the range of $4.0-5.0 \mathrm{mg} / \mathrm{g}$ (KMR-108, SI-3106, SI-1236 and SI-861/2).

According to the seed coat colours, we divided the 40 sesame seed lines in to four groups as brown, black, yellow and white. A one way ANOVA (between groups) showed the sesame seeds with brown seed coat had significantly high sesamin and sesamolin content than those with black, yellow or white seed coat $(\mathrm{P}=<0.05)$. Coefficient of Variation (CV) was used to study the variation in sesamin and sesamolin among the different seed coat colours. The results indicate that yellow $(71 \%)>$ white $(52 \%)>$ brown $(36 \%)$ $>$ black (32\%). The yellow seed coat sesame lines had more variation as compared to the other seed coat colours and yellow $(73 \%)>$ black $(41 \%)>$ brown $(29 \%)>$ white (2\%). With respect to sesamolin also yellow seed coat line exhibited more variation than sesame lines of other colours. The results of $\mathrm{CV}$ indicate that the sesame lines with yellow seed coat colour had more variation than those with brown, black or white seed coat. Coefficient of Correlation (CC) between sesamin and sesamolin indicated positive correlation by Pearson's correlation coefficient. Wang et al., (2013) showed darker seed coat colour sesame had highest positive correlation, as black $(R=0.96)$ showed highest CC for sesamin and sesamolin than those with yellow and white. Interestingly in the present study we observed highest $\mathrm{CC}$ in yellow seeded line for sesamin and sesamolin $(R=0.80)$ than brown, black or white.

The furofuran type of sesame lignan has innumerable beneficial effects on human health. The health promoting effects of sesame seeds in human body may be attributed to sesamin contents. Sesame lignan isolation attempts, especially sesamin and sesamolin have been made ever since 1940 when the synergistic effect of sesame oil for the insecticidal pyrethrins was reported (Tracy, 1958).

After that, the main focus has been made to isolate two of the major aglyconlignans especially, sesamin and sesamolin from varied sources (Hemalatha et al., 2004; Wang et al., 2012; Shi et al., 2017). Sesame lignan stimulate hepatic fatty acid oxidation by affecting the gene expression of various proteins regulating hepatic fatty acid oxidation (Ide et al., 2009). 
Int.J.Curr.Microbiol.App.Sci (2019) 8(6): 2329-2336

Table.1 The lignan contents in 40 sesame lines

\begin{tabular}{|c|c|c|c|c|}
\hline Name & Colour & $\begin{array}{c}\text { Sesamin } \\
(\mathrm{mg} / \mathrm{g})\end{array}$ & $\begin{array}{l}\text { Sesamolin } \\
(\mathrm{mg} / \mathrm{g})\end{array}$ & $\begin{array}{l}\text { Total Lignan } \\
(\mathrm{mg} / \mathrm{g})\end{array}$ \\
\hline IS-621 & $\mathrm{Br}$ & 1.24 & 1.26 & 2.50 \\
\hline KMR-95 & $\mathrm{Br}$ & 1.08 & 1.34 & 2.42 \\
\hline SI-1885 & $\mathrm{Br}$ & 1.59 & 2.06 & 3.65 \\
\hline SI-608 & $\mathrm{Br}$ & 0.71 & 0.79 & 1.51 \\
\hline SI-3106 & $\mathrm{Br}$ & 1.96 & 2.52 & 4.48 \\
\hline SI-4721 & $\mathrm{Br}$ & 1.81 & 1.66 & 3.46 \\
\hline IC-1994-38 & $\mathrm{Br}$ & 1.82 & 1.71 & 3.53 \\
\hline AST-5 & $\mathrm{Br}$ & 1.45 & 2.12 & 3.58 \\
\hline KMR-80 & $\mathrm{Br}$ & 1.78 & 2.15 & 3.93 \\
\hline SI-1769 & $\mathrm{Br}$ & 0.46 & 1.17 & 1.63 \\
\hline KMR-108 & $\mathrm{Br}$ & 2.58 & 1.98 & 4.55 \\
\hline DS-1 & $\mathrm{Br}$ & 1.82 & 1.90 & 3.71 \\
\hline SI-861/2 & $\mathrm{Br}$ & 1.87 & 2.18 & 4.05 \\
\hline BS-27 & $\mathrm{Br}$ & 1.48 & 1.20 & 2.68 \\
\hline SI-1657 & $\mathrm{Br}$ & 0.17 & 0.64 & 0.81 \\
\hline ES-13 & $\mathrm{Br}$ & 1.58 & 1.56 & 3.14 \\
\hline SI-3278/2 & $\mathrm{Br}$ & 1.95 & 1.51 & 3.46 \\
\hline SI-30-1 & $\mathrm{Br}$ & 1.77 & 1.58 & 3.35 \\
\hline SI-1861/2 & $\mathrm{Br}$ & 1.37 & 1.79 & 3.17 \\
\hline SI-9185 & $\mathrm{Br}$ & 0.94 & 1.03 & 1.97 \\
\hline SI-1818 & $\mathrm{Br}$ & 1.79 & 1.37 & 3.16 \\
\hline KMR-69 & $\mathrm{Br}$ & 1.82 & 1.32 & 3.15 \\
\hline SI-771 & $\mathrm{Br}$ & 1.45 & 1.75 & 3.20 \\
\hline SI-1236 & $\mathrm{B}$ & 1.82 & 2.35 & 4.17 \\
\hline SI-70 & B & 0.76 & 0.84 & 1.59 \\
\hline SP-7613 & B & 1.74 & 2.25 & 3.99 \\
\hline SI-837 & B & 0.98 & 1.06 & 2.04 \\
\hline PAIYUR-1 & B & 1.81 & 1.17 & 2.99 \\
\hline TKG-84 & B & 1.67 & 2.06 & 3.73 \\
\hline JLS-57 & $\mathrm{Y}$ & 0.24 & 0.26 & 0.49 \\
\hline SI-1804 & $\mathrm{Y}$ & 1.15 & 1.46 & 2.61 \\
\hline NIC-8261 & Y & 0.61 & 1.64 & 2.24 \\
\hline SO-233 & $\mathrm{Y}$ & 0.34 & 0.38 & 0.72 \\
\hline SI-7212 & $\mathrm{Y}$ & 0.78 & 0.82 & 1.60 \\
\hline NIC-1610 & $\mathrm{Y}$ & 1.58 & 2.37 & 3.95 \\
\hline DCP-1810 & Y & 0.82 & 0.51 & 1.32 \\
\hline SI-1712 & $\mathrm{Y}$ & 0.08 & 0.64 & 0.72 \\
\hline KMR-7 & W & 0.55 & 0.65 & 1.19 \\
\hline ESN-32 & W & 1.35 & 0.63 & 1.99 \\
\hline TC-25 & $\mathrm{W}$ & 0.65 & 0.66 & 1.30 \\
\hline
\end{tabular}


Fig.1 HPLC separation of lignans in sesame lines a) KMR-108 and b) JLS-57

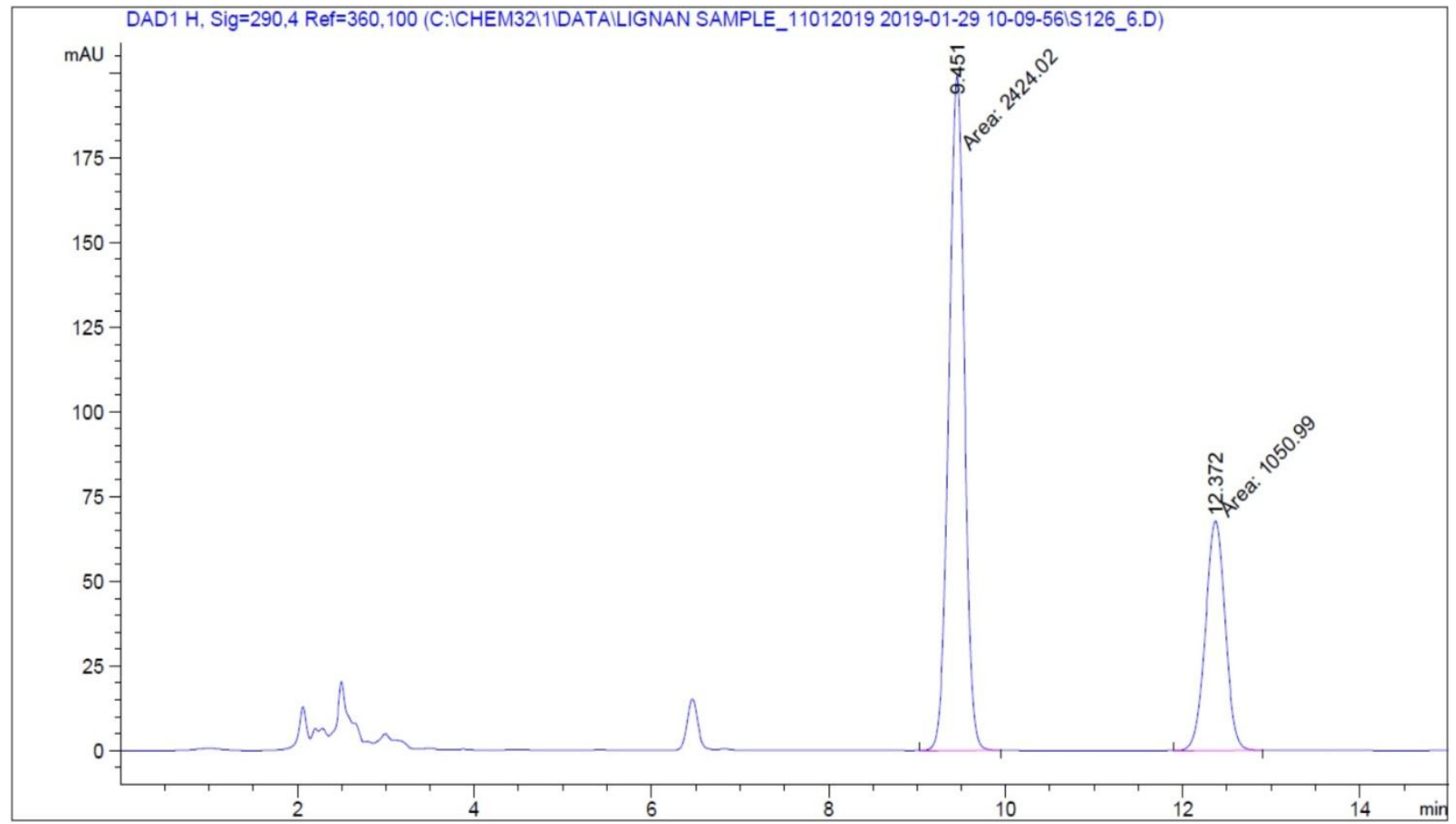

a) KMR-108

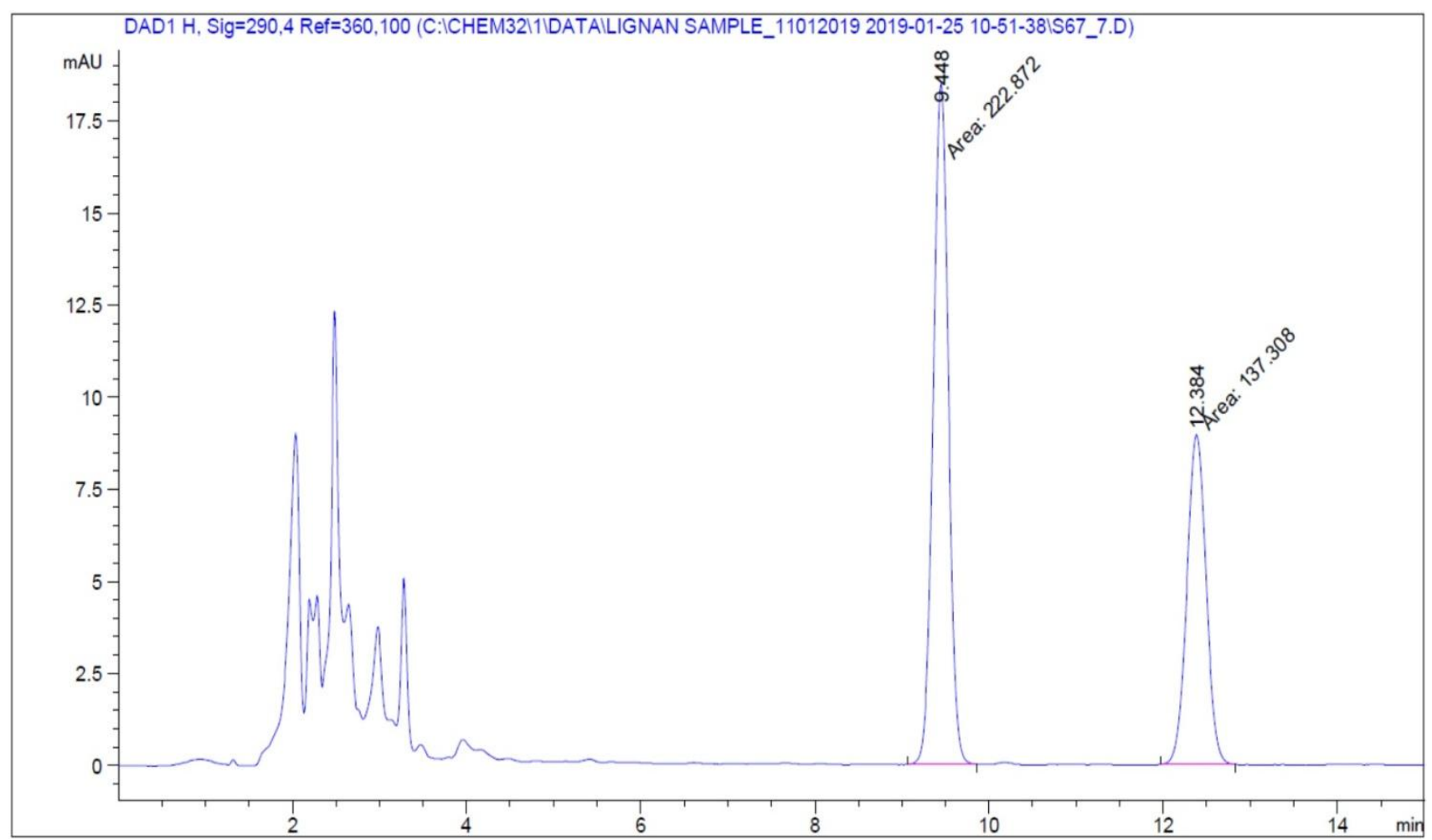

b) JLS-5 
Fig.2 Distribution plot for content of a) total lignan, b) sesamin and c) sesamolin among in 40 sesame lines
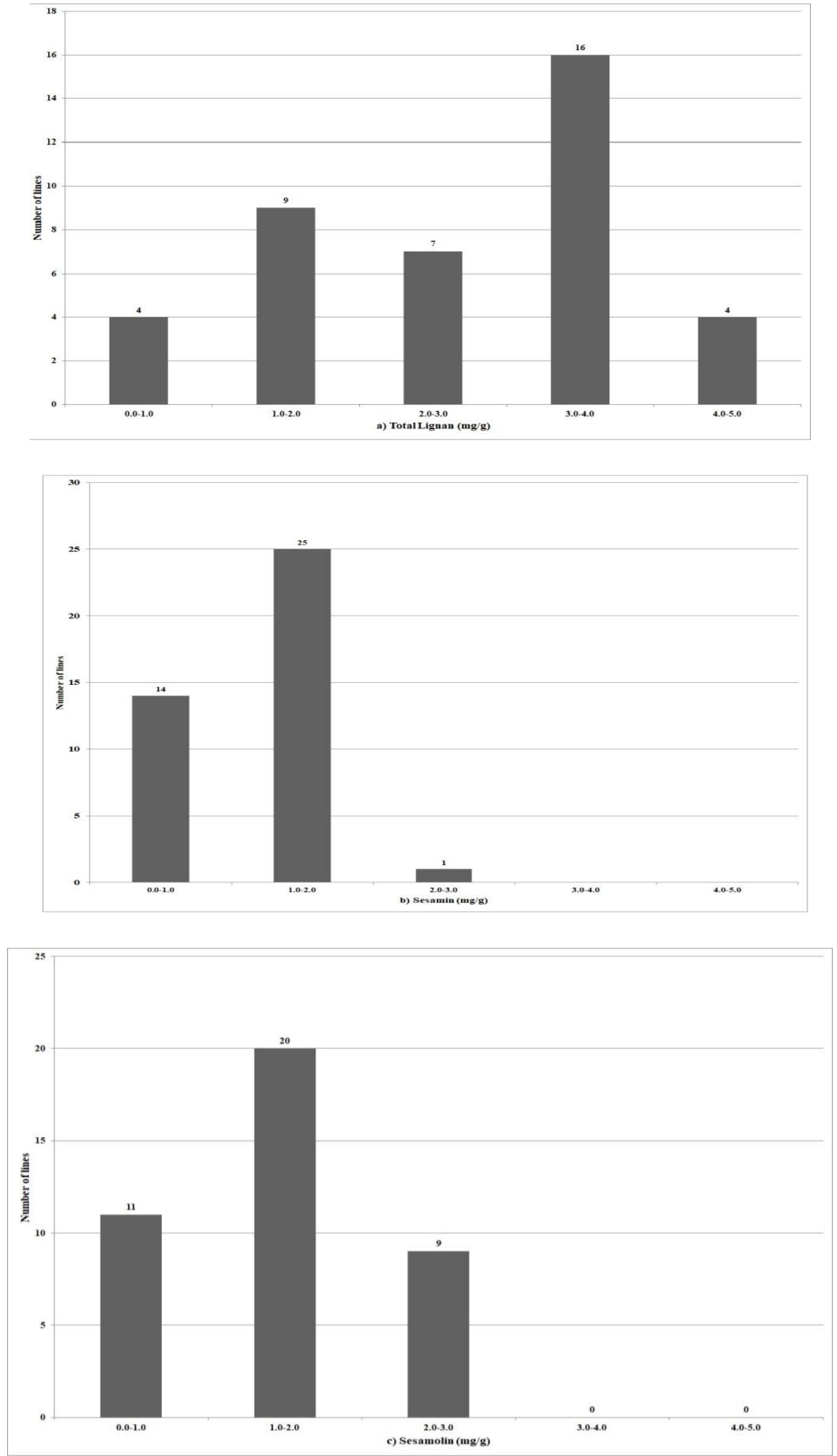
Sesame lignan contributes to the lowering of triglycerides in blood by promoting fatty acid oxidation. Anti-aging property of the isolated lignans was studied using Caenorhabditis elegans as a relevant animal model to develop anti-aging agents ( $\mathrm{Su}$ et al., 2015).

Phitak et al., (2012) opined that "sesamin may be a natural drug of choice for treatment of arthritic diseases". Intervention and epidemiological studies on dietary intake of lignans in relation to cardiovascular disease risk indicated high lignan doses decreased the risk of cardiovascular disease (Peterson et al., 2010). This study established the positive effect of lignans in preventing cardiovascular diseases. The associations between lignans and decreased risk of cardiovascular disease are promising, but are yet not well established, perhaps due to low lignan intakes in human diet. Our study provides valuable information on lignans especially sesamin and sesamolin contents in sesame seeds and can identify the potential germplasmlines for breeding sesame lines with high lignan contents.

In the present study we observed greater variation in sesamin and sesamolin contents in 40 sesame lines maintained in Tamil Nadu Agricultural University, Tamil Nadu. Among these KMR-108, SI-3106, SI-1236 and SI$861 / 2$ had highest content of sesamin and sesamolin, indicating that these lines can be use as functional food. It has a high lignan value we can use it in cosmetic industries or in pharmaceutics industries etc. The lines with high lignan content may be ideal for breeding programme to evolve high oil yielding lines with high levels of sesamin and seamolin.

\section{References}

Bisht, I. S., Mahajan, R. K., Loknathan, T. R., \&Agrawal, R. C. (1998). Diversity in Indian sesame collection and stratification of germplasm accessions in different diversity groups. Genetic Resources and Crop Evolution, 45(4), 325-335.

Hemalatha, S. (2004).Lignans and tocopherols in Indian sesame cultivars. Journal of the American Oil Chemists' Society, 81:467.

Hsu, D. Z., Su, S. B., Chien, S. P., Chiang, P. J., Li, Y. H., Lo, Y. J., and Liu, M. Y. (2005). Effect of sesame oil on oxidative-stress-associated renal injury in endotoxemic rats: involvement of nitric oxide and proinflammatory cytokines. Shock, 24(3), 276-280.

Hussein, Y., Amin, G., and Gahin, H. (2016). Antioxidant Activities during Drought Stress Resistance of Sesame (Sesamum indicum L.) Plant by Salicylic Acid and Kinetin. Research Journal of Botany, 11(1-3), 1-8.

Ide, T., Nakashima, Y., Iida, H., Yasumoto, S., and Katsuta, M. (2009). Lipid metabolism and nutrigenomics-impact of sesame lignans on gene expression profiles and fatty acid oxidation in rat liver.In Food Factors for Health Promotion (Vol. 61, pp. 10-24).Karger Publishers.

Latif, S., and Anwar, F. (2011).Aqueous enzymatic sesame oil and protein extraction. Food chemistry, 125:679684.

Pathak, N., Bhaduri, A., Bhat, K. V., and Rai, A. K. (2015). Tracking sesamin synthase gene expression through seed maturity in wild and cultivated sesame species-a domestication footprint. Plant biology, 17:1039-1046.

Peñalvo, J. L., Hopia, A., and Adlercreutz, H. (2006).Effect of sesamin on serum cholesterol and triglycerides levels in LDL receptor-deficient mice. European journal of nutrition, 45(8), 439

Peterson, J., Dwyer, J., Adlercreutz, H., Scalbert, A., Jacques, P., and 
McCullough, M. L. (2010). Dietary lignans: physiology and potential for cardiovascular disease risk reduction. Nutrition reviews, 68:571-603.

Phitak, T., Pothacharoen, P., Settakorn, J., Poompimol, W., Caterson, B., and Kongtawelert, P. (2012). Chondroprotective and antiinflammatory effects of sesamin.Phytochemistry, 80:77-88.

Shahidi, F., Liyana-Pathirana, C. M., and Wall, D. S. (2006).Antioxidant activity of white and black sesame seeds and their hull fractions. Food Chemistry, 99:478-483.

Shi, L. K., Liu, R. J., Jin, Q. Z., and Wang, X. G. (2017).The contents of lignans in sesame seeds and commercial sesame oils of China. Journal of the American Oil Chemists' Society, 94:1035-1044.

Su, S., and Wink, M. (2015). Natural lignans from Arctiumlappa as antiaging agents in Caenorhabditis elegans. Phytochemistry, 117, 340-350.

Suja, K. P., Abraham, J. T., Thamizh, S. N., Jayalekshmy, A., and Arumughan, C.
(2004). Antioxidant efficacy of sesame cake extract in vegetable oil protection. Food Chemistry, 84:393-400.

Tracy, R. L. (1958). U.S. Patent No. 2,837,534. Washington, DC: U.S. Patent and Trademark Office.

Wang, L., Zhang, Y., Li, P., Wang, X., Zhang, W., Wei, W., and Zhang, X. (2012). HPLC analysis of seed sesamin and sesamolin variation in a sesame germplasm collection in China. Journal of the American Oil Chemists' Society, 89:1011-1020.

Wang, L., Zhang, Y., Li, P., Zhang, W., Wang, X., Qi, X., and Zhang, X. (2013).Variation of sesamin and sesamolin contents in sesame cultivars from China. Pak J Bot, 45, 177-182.

Yokota, T., Matsuzaki, Y., Koyama, M., Hitomi, T., Kawanaka, M., Enoki- Konishi, M., and Osawa, T. (2007). Sesamin, a lignan of sesame, down- regulates cyclin D1 protein expression in human tumor cells. Cancer science, 98(9), 1447-1453.

\section{How to cite this article:}

Ghane Ajit, D. Uma, S. Manonmani, B. Vinothkumar and Rajesh, S. 2019. Diversity Analysis of Sesame Lignans in 40 Sesame Collections in Tamil Nadu, India. Int.J.Curr.Microbiol.App.Sci. 8(06): 2329-2336. doi: https://doi.org/10.20546/ijcmas.2019.806.276 